OPEN ACCESS

Edited by:

Rajesh K. Sani,

South Dakota School of Mines and Technology, United States

Reviewed by:

Jeremy Semrau,

University of Michigan, United States

Sachin Kumar

Sardar Swaran Singh National Institute of Renewable Energy, India

*Correspondence:

Michael T. Guarnien michael.guarnieri@nrel.gov

Specialty section:

This article was submitted to Microbiotechnology, Ecotoxicology and Bioremediation,

a section of the journal

Frontiers in Microbiology

Received: 31 May 2018 Accepted: 12 October 2018 Published: 31 October 2018

Citation:

Henard CA, Franklin TG, Youhenna B, But S, Alexander D, Kalyuzhnaya MG and Guarnieri MT (2018) Biogas Biocatalysis: Methanotrophic Bacterial Cultivation, Metabolite Profiling, and Bioconversion to Lactic Acid.

Front. Microbiol. 9:2610. doi: 10.3389/fmicb.2018.02610

\section{Biogas Biocatalysis: Methanotrophic Bacterial Cultivation, Metabolite Profiling, and Bioconversion to Lactic Acid}

\author{
Calvin A. Henard ${ }^{1}$, Tyler G. Franklin ${ }^{1}$, Batool Youhenna ${ }^{2}$, Sergey But ${ }^{3}$, Danny Alexander ${ }^{4}$, \\ Marina G. Kalyuzhnaya ${ }^{2}$ and Michael T. Guarnieri ${ }^{\text {t* }}$
}

${ }^{1}$ National Renewable Energy Laboratory, National Bioenergy Center, Golden, CO, United States, ${ }^{2}$ Biology Department, San Diego State University, San Diego, CA, United States, ${ }^{3}$ Skryabin Institute of Biochemistry and Physiology of Microorganisms, Moscow, Russia, ${ }^{4}$ Metabolon, Inc., Durham, NC, United States

Anaerobic digestion (AD) of waste substrates, and renewable biomass and crop residues offers a means to generate energy-rich biogas. However, at present, AD-derived biogas is primarily flared or used for combined heat and power (CHP), in part due to inefficient gas-to-liquid conversion technologies. Methanotrophic bacteria are capable of utilizing methane as a sole carbon and energy source, offering promising potential for biological gas-to-liquid conversion of AD-derived biogas. Here, we report cultivation of three phylogenetically diverse methanotrophic bacteria on biogas streams derived from AD of a series of energy crop residues. Strains maintained comparable central metabolic activity and displayed minimal growth inhibition when cultivated under batch configuration on AD biogas streams relative to pure methane, although metabolite analysis suggested biogas streams increase cellular oxidative stress. In contrast to batch cultivation, growth arrest was observed under continuous cultivation configuration, concurrent with increased biosynthesis and excretion of lactate. We examined the potential for enhanced lactate production via the employ of a pyruvate dehydrogenase mutant strain, ultimately achieving $0.027 \mathrm{~g}$ lactate $/ \mathrm{g} \mathrm{DCW} / \mathrm{h}$, the highest reported lactate specific productivity from biogas to date.

Keywords: methane, methanotroph, biogas, anaerobic digestion, lactic acid, methane biocatalysis, biogas upgrading

\section{INTRODUCTION}

Methanotrophic bacteria can use methane $\left(\mathrm{CH}_{4}\right)$, the primary component of natural gas and anaerobic digestion $(\mathrm{AD})$-derived biogas, as a sole carbon and energy source, presenting a promising biological route for atmospheric $\mathrm{CH}_{4}$ sequestration, bioremediation, and gas-to-liquid conversion for industrial applications (Kalyuzhnaya et al., 2015; Strong et al., 2015, 2016; Pieja et al., 2017). To this latter end, we have recently reported a biocatalytic route for methane conversion to lipid fuel intermediates and platform chemicals, as well as metabolic engineering strategies to enhance carbon conversion efficiency of biological gas-to-liquid conversion processes (Henard et al., 2016, 2017). Additional recent reports have demonstrated methane bioconversion to diverse product suites, including single cell protein, methanol, carboxylic acids, polyhydroxybutyrate, and 
2,3-butanediol (Bothe et al., 2002; Hwang et al., 2014; Cal et al., 2016; Myung et al., 2016; Garg et al., 2018; Nguyen et al., 2018), further underscoring the potential power of methanotrophic bioconversion strategies.

Aerobic methanotrophs are ubiquitous in nature and serve as a primary environmental $\mathrm{CH}_{4}$ sink, significantly contributing to the global biogeochemical carbon cycle (Anthony, 1982). An array of methanotrophic bacteria have been isolated in pure culture and primarily belong to the diverse classes of gamma- and alphaproteobacterial (Hanson and Hanson, 1996). The gammaproteobacteria Methylococcus capsulatus Bath and alphaproteobacteria Methylosinus trichosporium OB3b have served as models for understanding the fundamentals of methanotrophy and have defined two primary pathways for $\mathrm{CH}_{4}$ assimilation in these organisms, the ribulose monophosphate pathway (RuMP) and the serine cycle, respectively. With a resurgent interest in applied methanotrophy (Conrado and Gonzalez, 2014; Haynes and Gonzalez, 2014; Strong et al., 2015; Clomburg et al., 2017), several novel methanotrophs have recently been isolated and their genomes sequenced, providing further insight into $\mathrm{CH}_{4}$ metabolism and the development of genome scale models (Boden et al., 2011; Khmelenina et al., 2013; Kits et al., 2013; Hamilton et al., 2015; Flynn et al., 2016; Akberdin et al., 2018).

Among the most promising of these recently isolated methanotrophs are the gammaproteobacterial, haloalkaliphilic members of the genus Methylomicrobium, including Methylomicrobium alcaliphilum $20 \mathrm{Z}^{\mathrm{R}}$ and Methylomicrobium buryatense $5 \mathrm{G}(\mathrm{B1})$, which have established genetic tools and genome scale models (Ojala et al., 2011; Gilman et al., 2015; la Torre et al., 2015; Puri et al., 2015; Henard et al., 2016; Yan et al., 2016; Akberdin et al., 2018). Several methanotrophic strains possess unique characteristics for biotechnological deployment, including differential growth rates, cultivation parameters, flux to metabolic intermediates, and end-product tolerance. However, strain selection for industrial applications is not always obvious; while some basic considerations can be applied to all biological $\mathrm{CH}_{4}$ oxidation processes, the selection of a microbial catalyst is influenced by the type of application to be developed, including substrate source, product selection, and ultimately, the overall process economics of the technology (Kalyuzhnaya, 2016). Additionally, though bioconversion parameters are well-defined for pure $\mathrm{CH}_{4}$ in the above-described strains, the potential for methanotrophic cultivation and bioproduction on renewable, $\mathrm{AD}$-derived biogas remains to be fully evaluated, limiting adoption, and impact as a core gas-to-liquid technology.

Biogas derived from $\mathrm{AD}$ of waste stream sources such as municipal solid waste operations, biorefineries, and agricultural operations, offers a versatile renewable energy source. At present, biogas is primarily used to produce combined heat and power (CHP). Alternatively, AD biogas can be scrubbed for conversion to biomethane that can, in turn, be utilized as a renewable option in natural gas applications. Total domestic methane potential from landfill material, animal manure, wastewater, and organic waste (food waste) is estimated to be $>400$ TBtu (Department of Energy, 2017). Additionally, biogas generated from $\mathrm{AD}$ of lignocellulosic biomass resources is estimated to offer $>4$ quadrillion Btu potential energy (Department of Energy, 2017). This energy potential could displace nearly half of current domestic natural gas consumption in the electric power sector and all current natural gas consumption in the transportation sector (Department of Energy, 2017). Despite the promise of biogas as a high-volume, renewable energy source and natural gas replacement, its gaseous state prevents facile integration with extant transportation and industrial infrastructure. Additionally, biogas composition varies significantly depending upon input feedstock, but it is typically comprised of $40-65 \% \mathrm{CH}_{4}, 30-$ $40 \%$ carbon dioxide $\left(\mathrm{CO}_{2}\right)$, and gaseous impurities, including hydrogen sulfide $\left(\mathrm{H}_{2} \mathrm{~S}\right)$, ammonia, and siloxanes (Hosseini and Wahid, 2014).

In this study we explored the applicability of phylogenetically diverse methanotrophic bacteria for $\mathrm{AD}$ biogas utilization and conversion. We tested six variable sources of biogas derived from $\mathrm{AD}$ of energy crops and derivatives thereof, conducting comparative growth analyses of three representative methanotrophic cultures, $M$. capsulatus Bath, M. trichosporium $\mathrm{OB} 3 \mathrm{~b}$, and $M$. alcaliphilum $20 \mathrm{Z}^{\mathrm{R}}$. The impact of the various biogas streams on cellular metabolism was further investigated in M. alcaliphilum $20 \mathrm{Z}^{\mathrm{R}}$ using global metabolomics analysis. Lastly, we demonstrated biogas conversion to lactate at the highest reported specific productivity to date by a rationally engineered M. alcaliphilum $20 \mathrm{Z}^{\mathrm{R}}$ pyruvate dehydrogenase mutant.

\section{MATERIALS AND METHODS}

\section{Bacterial Strains and Cultivation}

Methylomicrobium alcaliphilum 20Z $\mathrm{Z}^{\mathrm{R}}$ (Akberdin et al., 2018), Methylosinus trichosporium OB3b, and Methylococcus capsulatus Bath were cultivated in either nitrate mineral salts (NMS) medium (Bath and OB3b) or NMS medium supplemented with $3 \% \mathrm{NaCl}$ and carbonate buffer as previously described (Whittenbury et al., 1970; Akberdin et al., 2018). To determine optimal biogas concentration and biogas effects on growth, cultures were grown in $250 \mathrm{ml}$ vials containing $50 \mathrm{ml}$ of growth medium. After inoculation at a starting density of $\mathrm{OD}_{600}=$ 0.10 , the vials were crimped with butyl (gray or red) stoppers to create gas-tight seals. Increasing concentrations of mock biogas ( $60 \% \mathrm{CH}_{4} / 40 \% \mathrm{CO}_{2}$ ) or pure $\mathrm{CH}_{4}$ was added to the headspace to determine the optimal biogas concentration for growth. Biogas samples BG1-6 were added to the headspace [33\% biogas $\left(\sim 20 \% \mathrm{CH}_{4}\right)$ in air] of serum vials to evaluate their effects on methanotrophic growth. Cultures containing pure $\mathrm{CH}_{4}$ were supplemented with nitrogen to equilibrate the volume of gas added to the corresponding biogas serum vial. Cultures were incubated at $30^{\circ} \mathrm{C}\left(20 \mathrm{Z}^{\mathrm{R}}\right.$ and $\left.\mathrm{OB} 3 \mathrm{~b}\right)$ or $37^{\circ} \mathrm{C}$ (Bath) with orbital shaking at $200 \mathrm{rpm}$, and bacterial growth was measured spectrophotometrically. A second series of parallel cultures were set up for headspace composition $\left(\mathrm{CH}_{4}, \mathrm{~N}_{2}, \mathrm{O}_{2}, \mathrm{CO}_{2}\right.$, and $\mathrm{CO}$ ) analyses and biomass yield. At each timepoint, samples of the headspace $(1 \mathrm{ml})$ were injected into an SRI GC system for gas chromatography analyses. Gas consumption data were collected at the beginning and completion of each experiment. The concentrations were estimated using standard gas mixtures (Scotty Analyzed gases, Supelco Analytical, Sigma-Aldrich). Dry 
Cell Weight (DCW) was either measured directly after freezedrying or estimated from the final OD of the cell culture using the following equation: $\mathrm{DCW}=\mathrm{OD} *(0.35 \pm 0.04 \mathrm{~g} / \mathrm{L})$ (Akberdin et al., 2018). Biomass yield data $\left(\mathrm{Y}_{\mathrm{CH} 4}\right)$ were calculated using dry cell weight and consumed substrate data and represented as $\mathrm{g}$ biomass produced per $\mathrm{g} \mathrm{CH}_{4}$ consumed.

\section{Anaerobic Digestion and Biogas Generation}

Various feedstock substrates were received from Idaho National Laboratory, the Ohio Soybean Council, Aemetis, and University of Illinois, Urbana-Champaign. Continuous digestions were performed in six lab-scale digesters operating at $14-\mathrm{L}$ net volume per digester, which were inoculated with digester content obtained from East Bay Municipal Utility District and a local dairy (Straus, CA). Reactors were stabilized to yield equal base load gas production and began continuous operation at a loading rate ramped up to $2 \mathrm{~kg}$ organic dry matter per cubic meter reactor volume per day with a target hydraulic retention (HRT) of 21-28 days and run time of 2.5 HRT, monitoring for gas flow, $\mathrm{pH}$ and gas composition. We characterized the material composition, the theoretical biogas and $\mathrm{CH}_{4}$ yield per the models of Buswell and Baserga (Achinas and Euverink, 2016), as well as the batch yield per VDI 4630 for soybean residues, corn stover, miscanthus, switchgrass, sorghum, bagasse, and two different ethanol stillage streams. In the continuous operation, we measured and quantified gas composition using gas chromatography compared to known standards.

\section{Metabolite Profiling}

Intracellular metabolites were analyzed by Metabolon, Inc. (Durham, NC) from M. alcaliphilum $20 \mathrm{Z}^{\mathrm{R}}$ cultured in serum vials with the headspace supplemented with $33 \%$ biogas ( 20\% $\left.\mathrm{CH}_{4}\right)$ in air as described above. Cells were collected by centrifugation when cultures reached $\mathrm{OD}_{600}=0.6-0.7$ and frozen in liquid nitrogen and stored at $-80^{\circ} \mathrm{C}$ prior to shipping to Metabolon. Metabolomic profiles were collected and processed as previously described (Henard et al., 2017; Akberdin et al., 2018). Changes in cell samples grown on biogas were compared to cell cultures grown on equivalent concentrations of $\mathrm{CH}_{4}$. Welch's two-sample $t$-tests and Principal Component Analysis (PCA) were used to analyze the data. For all analyses, following normalization to protein measured by Bradford, missing values, if any, were imputed with the observed minimum for that particular compound. The statistical analyses were performed on natural log-transformed data and were considered significant if $p$ $<0.05$.

\section{Mutant Construction}

Strains, plasmids, and primers used for amplification of upstream and downstream regions for construction of the pyruvate dehydrogenase $(p d h)$ knockout are shown in Table S1. Genomic fragments, $\sim 600$-bp of sequences flanking the dihydrolipoamide acetyltransferase subunit of the pyruvate dehydrogenase complex (MALCv4_1358) gene, were amplified by PCR, and cloned into pCM184::Gm ${ }^{\mathrm{R}}$ plasmid at AatII/NcoI (upstream region) and SacI/SacII (downstream region) sites. The
TABLE 1 | Composition of tested biogas samples.

\begin{tabular}{lccccl}
\hline $\begin{array}{l}\text { Gas } \\
\text { sample ID }\end{array}$ & Substrate & $\begin{array}{c}\mathbf{C H}_{\mathbf{4}} \\
\mathbf{( \% )}\end{array}$ & $\begin{array}{c}\mathbf{C O}_{\mathbf{2}} \\
\mathbf{( \% )}\end{array}$ & $\begin{array}{c}\mathbf{H}_{\mathbf{2}} \mathbf{S} \\
\mathbf{( p p m )}\end{array}$ & Trace (<250 ppm) \\
\hline BG1 & Sorghum & 49 & 50 & 2,100 & $\mathrm{CO}$ \\
BG2 & Corn stover & 51 & 49 & 350 & CO, Carbonyl sulfide (COS) \\
BG3 & PEl syrup & 67 & 33 & 14,000 & Hexane, CO, COS \\
BG4 & Bagasse & 48 & 52 & 200 & CO, COS \\
BG5 & $\begin{array}{c}\text { Corn distiller's } \\
\text { solids syrup }\end{array}$ & 63 & 37 & 13,000 & CO, COS, C-5, C-6 \\
BG6 & Miscanthus & 52 & 49 & 80 & CO \\
\hline
\end{tabular}

resulting plasmid was introduced to the $20 \mathrm{Z}^{\mathrm{R}}$ strain by biparental conjugation as described previously (Puri et al., 2015). After mating, gentamycin-resistant clones were selected on medium supplemented with acetate $(5 \mathrm{mM})$, rifampicin $(50 \mu \mathrm{g} / \mathrm{mL})$, and gentamycin $(30 \mu \mathrm{g} / \mathrm{mL})$ to counter-select against $E$. coli. Then, the resulting colonies were PCR-genotyped for the absence of MALCv4_1358 gene followed by sequence verification.

\section{Continuous Gas Fermentation}

Fifty milliliter cultures of wild-type and $\Delta p d h:: \mathrm{Gm}^{\mathrm{R}} M$. alcaliphilum $20 \mathrm{Z}^{\mathrm{R}}$ were grown in $150 \mathrm{~mL}$ bubble columns with a continuous gas flow $\left(20 \% \mathrm{CH}_{4}\right.$ or $33 \%$ mock biogas in air, 1 vvm). At indicated intervals, $\mathrm{pH}$ was determined, growth was measured spectrophotometrically, and a $1 \mathrm{~mL}$ sample was taken for HPLC analysis. After $96 \mathrm{~h}$, bacteria were pelleted and freezedried to determine dry cell weight. HPLC was used to detect lactate in the culture supernatants. The culture supernatant was filtered using a $0.2 \mu \mathrm{m}$ syringe filter and then a $0.1 \mathrm{~mL}$ injection was separated using a model 1260 HPLC (Agilent, Santa Clara, CA) and a cation H HPx-87H column (Bio-Rad). A $0.6 \mathrm{~mL} / \mathrm{min}$ flow rate at $55^{\circ} \mathrm{C}$ with $0.01 \mathrm{~N}$ sulfuric acid as the mobile phase was used. DAD detection was measured at $220 \mathrm{~nm}$ and referenced at $360 \mathrm{~nm}$, and metabolite concentrations were calculated by regression analysis compared to known standards. The identity of lactate was also confirmed by NMR analysis.

\section{RESULTS AND DISCUSSION}

\section{Anaerobic Digestion of Crop Residues}

$\mathrm{AD}$ substrates were loaded into six 14-L lab scale continuously operating digesters. Steady state off-gas analyses, including $\mathrm{H}_{2} \mathrm{~S}$ and other contaminants, are shown in Table 1. The $\mathrm{CH}_{4}$ and $\mathrm{CO}_{2}$ content were found to be consistently between $48-67 \%$ and $33-52 \%$, respectively. The trace gases ethane, propane, $\mathrm{n}$-butane, and n-propane were detected at $<250 \mathrm{ppm}$ in all biogas streams. $\mathrm{H}_{2} \mathrm{~S}$ content varied significantly between 80 and $14,000 \mathrm{ppm}$, with the highest $\mathrm{H}_{2} \mathrm{~S}$ content found in the BG3 derived from a feedstock that is much higher in protein content compared to the other $\mathrm{AD}$ substrates, which increases gaseous sulfur components but also increases the $\mathrm{CH}_{4}$ content of the gas stream (Achinas and Euverink, 2016). 
TABLE 2 | Microbial cultures parameters on varied biogas streams.

\begin{tabular}{|c|c|c|c|c|c|c|}
\hline \multirow[t]{2}{*}{ Carbon source } & \multicolumn{2}{|c|}{$\begin{array}{c}\text { M. alcaliphilum } \\
20 \mathrm{Z}^{\mathrm{R}}\end{array}$} & \multicolumn{2}{|c|}{$\begin{array}{c}\text { M. capsulatus } \\
\text { Bath }\end{array}$} & \multicolumn{2}{|c|}{$\begin{array}{c}\text { M. trichosporium } \\
\text { ОВ3b }\end{array}$} \\
\hline & $Y_{B}$ & $T_{d}$ & $Y_{B}$ & $T_{d}$ & $Y_{B}$ & $T_{d}$ \\
\hline $\mathrm{CH}_{4}$ & 1.03 & 5.84 & 0.85 & 6.72 & 0.78 & 10.9 \\
\hline BG1 & 0.95 & 7.38 & 0.81 & 13.0 & 0.69 & 14.9 \\
\hline BG2 & 0.93 & 7.53 & 0.86 & 7.74 & 0.68 & 12.7 \\
\hline BG3 & 0.96 & 6.03 & 0.87 & 6.95 & 0.73 & 8.63 \\
\hline BG4 & 0.95 & 7.49 & 0.94 & 7.98 & 0.73 & 13.0 \\
\hline BG5 & 0.96 & 6.46 & 0.93 & 7.00 & 0.70 & 9.50 \\
\hline BG6 & 0.60 & 11.0 & 0.40 & 12.1 & 0.71 & 12.7 \\
\hline
\end{tabular}

$Y_{B}$, biomass yield ( $\left.\mathrm{g} \mathrm{DCW} / \mathrm{g} \mathrm{CH} \mathrm{CH}_{4}\right) ; T_{d}$, doubling time (h). The data represent the mean 2-3 independent observations.

\section{Methanotroph Culture Parameters on AD-Derived Biogas}

Methanotrophic bacteria require oxygen to activate $\mathrm{CH}_{4}$. Thus, AD-derived biogas will require mixing with air or pure oxygen before delivery to a methanotrophic biocatalyst. Further, $\mathrm{CO}_{2}, \mathrm{H}_{2} \mathrm{~S}$, and other biogas components have the potential to negatively affect bacterial growth. To determine the optimal biogas:air ratio we compared the growth of three diverse methanotrophs with mock biogas $\left(60 \% \mathrm{CH}_{4}, 40 \%\right.$ $\mathrm{CO}_{2}, 0.01 \% \mathrm{H}_{2} \mathrm{~S}$ ) or pure $\mathrm{CH}_{4}$ at varying concentrations ranging from $3.5 \%$ to $30 \% \mathrm{CH}_{4}$. The growth of all strains positively correlated to $\mathrm{CH}_{4}$ concentration in the headspace, presumably due to increased gas availability in the medium, with strains cultivated on $15-30 \% \mathrm{CH}_{4}$ displaying optimal growth (Figure 1). Further, we observed no difference in growth between cultures supplied with biogas or pure $\mathrm{CH}_{4}$, suggesting that high $\mathrm{CO}_{2}$ levels $(20 \% \mathrm{v} / \mathrm{v})$ does not negatively affect these organisms under these growth conditions (Figure 1). Interestingly, cultures exhibited optimal growth with a much higher $\mathrm{CH}_{4}: \mathrm{O}_{2}$ ratio (3:1) than is conventionally used for methanotroph cultivation (1.25:1), indicating that methanotrophic growth is not oxygen limited under our experimental conditions.

We next evaluated methanotrophic growth on the six ADderived biogas streams (Table 2). The growth of M. alcaliphilum $20 \mathrm{Z}^{\mathrm{R}}$ was inhibited by biogas originating from miscanthus silages (BG6); however, the strain grew comparable to pure $\mathrm{CH}_{4}$ on all other biogases. M. capsulatus Bath growth was inhibited by both sorghum (BG1)-and miscanthus (BG6)derived biogases, while $M$. trichosporium OB3b was only slightly inhibited by sorghum (BG1)-derived biogas. Interestingly, OB3b displayed increased growth kinetics in PEI syrup (BG3)- and CDS syrup (BG5)-derived biogas streams. Collectively, all three cultures displayed growth capacity on biogas with only minor alterations in biomass yield from $\mathrm{CH}_{4}$. However, some differences in biomass yield and doubling time were observed between biogas streams, underscoring that biogas composition can dictate the methanotrophic biocatalyst most appropriate for its conversion.

\section{Biogas-Induced Metabolic Alterations}

In order to better understand the impacts of raw biogas feedstock on the growth of methanotrophic bacteria, a series of metabolomic experiments were carried out. Since $M$. alcaliphilum $20 \mathrm{Z}^{\mathrm{R}}$ was superior to the other cultures with respect to growth and efficiency of biogas conversion, this strain was further evaluated for biochemical profiling. A summary of metabolites significantly altered during cultivation on biogas is shown in Table S2. As expected from the growth inhibition data, biogas derived from miscanthus (BG6) led to the most significant metabolite alterations. A PCA plot revealed that the treatmentrelated variation between groups was only slightly greater than the biological noise within groups (Figure S1). This suggests that the treatments did not cause profound perturbations in metabolism relative to the control condition. Indeed, metabolites of core metabolic pathways, including glycolytic, tricarboxylic acid, and pentose phosphate/ribulose 5 phosphate pathway metabolites were similar between $\mathrm{CH}_{4}$ and the six AD-derived biogas samples (Table S2).

When compared to the pure $\mathrm{CH}_{4}$-grown controls, several metabolite alterations pointed to a general effect on redox state related to biogas feeding. The most significant difference in metabolites of biogas-grown samples were in the glutathione biosynthetic pathway (Figure 2). In five of the six treatments, the levels of oxidized glutathione (GSSG) were higher while reduced glutathione (GSH) was generally lower. The oxidation product of glutathione and cysteine, cysteine-glutathione disulfide, was also higher in all biogas-grown cells. The data indicate that the pure $\mathrm{CH}_{4}$-fed cells contained more favorable levels of reduced glutathione, as well as a greater capacity to produce the compound. Consistent with this, several gamma-glutamyl amino acids, which are co-products of glutathione recycling, were also lower in all the treatment groups. The main biosynthetic enzymes for GSH production, gamma-glutamylcysteine synthetase (GCS) and glutathione synthetase (GS), can also generate a side product, ophthalmate, when GCS incorporates 2-aminobutyrate instead of cysteine and then GS adds the glycine to this non-specific intermediate. We observed a conserved decrease in ophthalmate in all biogas-cultivated samples. Interestingly, ophthalmate has previously only been found in mammals and the cyanobacteria Synechocystis (Soga et al., 2006; Narainsamy et al., 2016). It is unknown whether ergothioneine and/or ophthalmate function as effective antioxidants in M. alcaliphilum $20 \mathrm{Z}^{\mathrm{R}}$, but our data suggest they are, along with GSH, associated with a general antioxidant response. However, there are very few reports detailing antioxidant responses or glutathione-mediated reactions in methanotrophic bacteria. Thus, the linked pathways could be targeted for further investigation for improving biogas utilization.

Compounds in other pathways also supported that biogastreated cells were more oxidized or experiencing higher relative oxidative stress. Elevation of sulfate and the histidine derivative ergothioneine was observed in all the biogas cultures (Table S2). Ergothioneine levels were roughly correlated with sulfate levels across the different biogas treatments. Also, various one-carbon derivatives of organic acids and amino acids (methylmalonate, methylsuccinate, $\mathrm{N}$-formylmethionine, 


2-methyserine) were higher in all the biogas treatments relative to the $\mathrm{CH}_{4}$ control. The metabolite measured as the most significantly altered during biogas cultivation was ribonate, the oxidation product of ribose (Table S2). This compound ranged from 10 - to 20 -fold higher than $\mathrm{CH}_{4}$-grown controls in all biogas cultivated samples. The enzyme ribose- 1 dehydrogenase is NADP+ dependent (in some organisms) and can serve to provide NADPH-reducing equivalents to the system. Other compounds, such as UDP-glucuronate and pyridoxate, which are more highly oxidized versions of common metabolites, were also higher in all the biogas-grown cells. The oxidation of UDPglucose to UDP-glucuronate by UDP-glucose dehydrogenase also produces reducing equivalents in the form of NADH. Taken together with the increased oxidized glutathione levels, these data support that components in biogas, $\mathrm{CO}_{2}$, and/or contaminants, alter the intracellular redox state of the methanotroph.

\section{Bioconversion of Biogas to Lactate in a Continuous Gas Flow Bioreactor}

Industrial processes employing methanotrophic bacteria currently operate using a continuous natural gas supply, and future industrial bioconversion of $\mathrm{AD}$-derived biogas will likely require a continuous gas fermentation mode. Thus, we evaluated M. alcaliphilum $20 \mathrm{Z}^{\mathrm{R}}$ growth in a mid-throughput gas fermentation reactor supplied with $33 \%$ biogas in air $\left(20 \% \mathrm{CH}_{4}\right.$, $13 \% \mathrm{CO}_{2}$ ) at 1 volume of gas per volume of liquid per minute. Surprisingly, we observed no bacterial growth under continuous biogas supply, potentially due to carbonic acid production as indicated by a significant drop in the $\mathrm{pH}$ of the culture medium (Figure 3A and Figure S2). Bacterial growth was restored by the addition of $\mathrm{KOH}$ that raised the $\mathrm{pH}$ of the medium to $\mathrm{pH} 9.5$ (Figure $3 \mathrm{~A}$ ), suggesting that $\mathrm{H}_{2} \mathrm{~S}$ or other biogas components not affecting culture $\mathrm{pH}$ did not affect bacterial growth. HPLC analysis of the culture medium showed that lactate was the primary organic acid secreted during cultivation under continuous gas supply, with equivalent lactate (between 80 and $120 \mathrm{mg} / \mathrm{L}$ ) detected from cultures grown with pure $\mathrm{CH}_{4}$ or biogas buffered with $\mathrm{KOH}$ after $72 \mathrm{~h}$ of cultivation (Figure 3B). Interestingly, we detected increased lactate production (between 220 and $280 \mathrm{mg} / \mathrm{L}$ ) from cultures with biogas-inhibited growth during the same cultivation timeframe (Figure 3B). Lactate is predicted to be synthesized by $M$. alcaliphilum $20 \mathrm{Z}^{\mathrm{R}}$ via the conversion of pyruvate to lactate by a lactate dehydrogenase (LDH, MALCv4_0534). We hypothesized that flux to lactate could be improved by removing pyruvate conversion to acetyl-CoA, the primary carbon flux during active growth of gammaproteobacterial methanotrophs mediated by the pyruvate dehydrogenase (Kalyuzhnaya et al., 2013; Akberdin et al., 2018). Indeed, we observed a significant increase in both lactate titer (2-3 fold) and specific productivity (four-fold) in a pyruvate dehydrogenase mutant compared to wild-type $M$. alcaliphilum $20 \mathrm{Z}^{\mathrm{R}}$ when cultured with continuous $\mathrm{CH}_{4}$ or biogas feed (Figure 4). These data suggest that this promising biocatalyst increases lactate biosynthesis and excretion in response to the low $\mathrm{pH}$ induced by biogas-derived carbonic acid, representing a promising fermentation configuration for organic
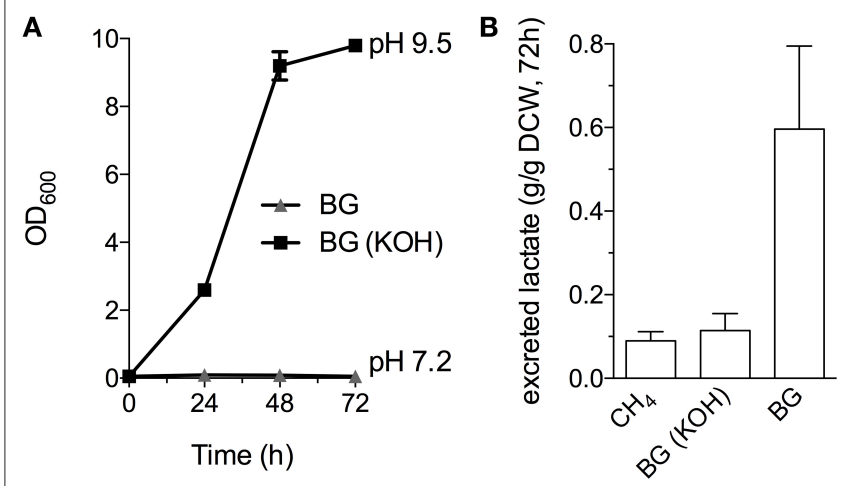

FIGURE 3 | M. alcaliphilum $20 Z^{\mathrm{R}}$ cultivation on a continuous biogas stream. (A) Bacterial growth with continuous supply of $33 \%$ biogas in air $\left(20 \% \mathrm{CH}_{4}\right.$, $13 \% \mathrm{CO}_{2}, 1 \mathrm{vvm}$ ) with (black square) or without (gray triangle) the addition of $0.4 \mathrm{~N}$ potassium hydroxide $(\mathrm{KOH})$. (B) Lactate excreted into the culture medium by $M$. alciliphilum supplied with $\mathrm{CH}_{4}$ or biogas (with or without $\mathrm{KOH}$ in the medium) detected by HPLC and normalized to dry cell weight (DCW). The data represent the average \pm S.D. from three independent observations.

acid production. Further, this represents the highest reported lactate specific productivity $(0.027 \mathrm{~g}$ lactate $/ \mathrm{gDWC} / \mathrm{h})$ in a methanotroph expressing its native LDH, significantly improved compared to our previous demonstrations of $\mathrm{CH}_{4}$ bioconversion to lactate (Henard et al., 2016). In addition to the deletion of the pyruvate dehydrogenase, overexpression of the native $M$. alcaliphilum $20 \mathrm{Z}^{\mathrm{R}} \mathrm{LDH}$ or a heterologous $\mathrm{LDH}$ with known minimal negative feedback regulation like the Lactobacillus helveticus $\mathrm{LDH}$, is a rational metabolic engineering target for increased pyruvate conversion to lactate (Henard et al., 2016; Garg et al., 2018).

\section{CONCLUSION}

Methanotrophic bacteria have recently gained intensified biotechnological interest due to their capacity to use methane as a sole carbon and energy source, in turn presenting a promising gas-to-liquid bioconversion pathway. Though numerous technology-to-market hurdles remain, these efforts serve as proof-of-concept for microbial conversion of $\mathrm{AD}$-derived biogas, notably presenting a modular, up-, and down-scalable, and highly selective route to fuel and chemical intermediates.

Our data indicate that cultivation of diverse methanotrophic bacteria is feasible on biogas derived from energy crops and residues, despite containing high levels of toxic contaminants. Metabolite profiling of $M$. alcaliphilum $20 \mathrm{Z}^{\mathrm{R}}$ supports that biogas components alter the intracellular redox state of this organism, which can be leveraged to guide future metabolic engineering efforts in development of efficient biogas biocatalysts. Importantly, we demonstrated bioconversion of biogas to lactate by M. alcaliphilum $20 \mathrm{Z}^{\mathrm{R}}$, and improved lactate specific productivity via rational strain engineering in this methanotroph. Lactate is a promising chemical precursor for the production of bioplastics (Abdel-Rahman et al., 2013; Eiteman and Ramalingam, 2015), and can also be used to generate an array 
A

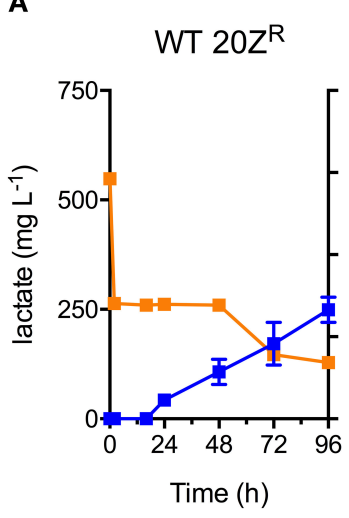

B

$\Delta p d h:: \mathrm{Gm}^{\mathrm{R}} 20 \mathrm{Z}^{\mathrm{R}}$

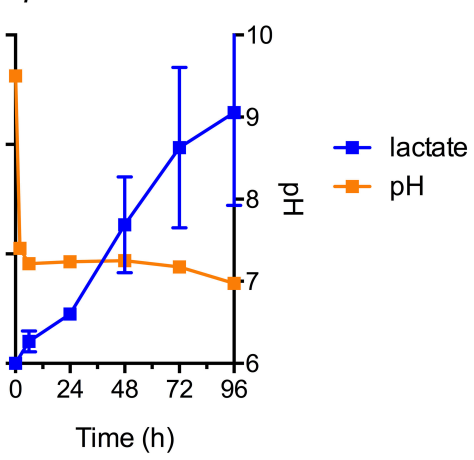

C

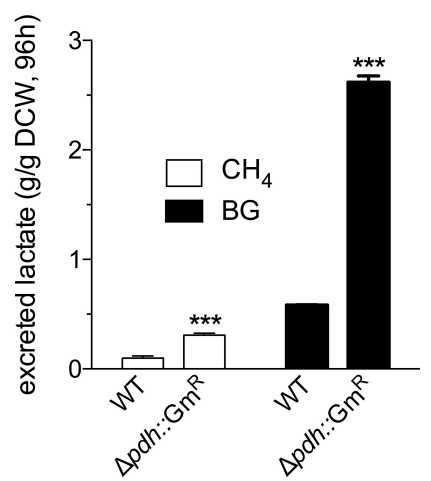

FIGURE 4 | A M. alcaliphilum 20Z ${ }^{\mathrm{R}}$ pyruvate dehydrogenase mutant exhibits increased flux to lactate. Excreted lactate (blue square), and culture pH (orange square) of wild-type (WT, A) and pyruvate dehydrogenase mutant $\left(\Delta p d h:: \mathrm{Gm}^{\mathrm{R}}\right.$, B) M. alcaliphilum $20 z^{\mathrm{R}}$ during cultivation with continuous supply of $33 \%$ biogas in air (20\% $\mathrm{CH}_{4}, 13 \% \mathrm{CO}_{2}, 1 \mathrm{vvm}$ ) (C) Lactate flux from pure $\mathrm{CH}_{4}$ (white bars) or biogas (black bars) in WT and $\Delta$ pdh::Gm ${ }^{\mathrm{R}} \mathrm{M}$. alcaliphilum $20 Z^{\mathrm{R}}$ based on dry cell weight (DCW). The data represent the average \pm S.D. from 2 to 4 independent observations. ${ }^{\star \star \star} p<0.001$ compared to wild-type controls.

of additional chemical building blocks, including acrylic acid, propylene glycol, and pentanol. These chemical intermediates, along with polymers and fuels that could be generated from biogas, offer a viable, renewable alternative to those generated from conventional carbohydrate feedstocks, which compete with food production. Biocatalysis of conventionally flared $\mathrm{AD}$ biogas has the added benefit of GHG reduction while also offering a means to concurrently liquefy and upgrade $\mathrm{CH}_{4}$, enabling its utilization in conventional transportation and industrial manufacturing infrastructure. Future integration of biogas biocatalysis into conventional $\mathrm{AD}$ and biorefinery infrastructure will provide insight into other opportunities for recycling and cost reductions, advancing a viable route to a greener bioeconomy.

\section{AUTHOR CONTRIBUTIONS}

$\mathrm{CH}, \mathrm{MG}$, and $\mathrm{MK}$ designed experiments and analyzed the data. $\mathrm{CH}, \mathrm{TF}, \mathrm{BY}, \mathrm{SB}$, and DA performed experiments. $\mathrm{CH}, \mathrm{MK}, \mathrm{DA}$, and MG wrote the manuscript. All authors approved the final version of the manuscript.

\section{FUNDING}

This work was authored in part by Alliance for Sustainable Energy, LLC, the manager and operator of the National Renewable Energy Laboratory for the U.S. Department of
Energy under Contract No. DE-AC36-08GO28308. Funding provided by the U.S. Department of Energy Office of Energy Efficiency and Renewable Energy Bioenergy Technologies Office DE-FOA-0001085. The views expressed in the article do not necessarily represent the views of the DOE or the U.S. Government. The U.S. Government retains and the publisher, by accepting the article for publication, acknowledges that the U.S. Government retains a non-exclusive, paid-up, irrevocable, worldwide license to publish or reproduce the published form of this work, or allow others to do so, for U.S. Government purposes.

\section{ACKNOWLEDGMENTS}

We would like to thank Drs. Lisa Stein and Mary Lidstrom for providing the Methylosinus trichosporium OB3b and Methylococcus capsulatus Bath strains, respectively. We also thank Renee Happs and Holly Rohrer of NREL for assistance with NMR and HPLC analyses, respectively. We thank Michael Schuppenhauer of Silver Hill Partners for generating biogas samples.

\section{SUPPLEMENTARY MATERIAL}

The Supplementary Material for this article can be found online at: https://www.frontiersin.org/articles/10.3389/fmicb. 2018.02610/full\#supplementary-material

\section{REFERENCES}

Abdel-Rahman, M. A., Tashiro, Y., and Sonomoto, K. (2013). Recent advances in lactic acid production by microbial fermentation processes. Biotechnol. Adv. 31, 877-902. doi: 10.1016/j.biotechadv.2013. 04.002

Achinas, S., and Euverink, G. J. W. (2016). Theoretical analysis of biogas potential prediction from agricultural waste. Resour. Efficient Technol. 2, 143-147. doi: 10.1016/j.reffit.2016.08.001

Akberdin, I. R., Thompson, M., Hamilton, R., Desai, N., Alexander, D., Henard, C. A., et al. (2018). Methane utilization in Methylomicrobium alcaliphilum 20ZR: a systems approach. Sci. Rep. 8, 1-13. doi: 10.1038/s41598-018-20574-z 
Anthony, C. (1982). The Biochemistry of Methylotrophs. London; New York, NY: Academic Press.

Boden, R., Cunliffe, M., Scanlan, J., Moussard, H., Kits, K. D., Klotz, M. G., et al. (2011). Complete genome sequence of the aerobic marine methanotroph Methylomonas methanica MC09. J. Bacteriol. 193, 7001-7002. doi: 10.1128/JB.06267-11

Bothe, H., Møller Jensen, K., Mergel, A., Larsen, J., Jørgensen, C., Bothe, H., et al. (2002). Heterotrophic bacteria growing in association with Methylococcus capsulatus (Bath) in a single cell protein production process. Appl. Microbiol. Biotechnol. 59, 33-39. doi: 10.1007/s00253-002-0964-1

Cal, A. J., Sikkema, W. D., Ponce, M. I., Franqui-Villanueva, D., Riiff, T. J., Orts, W. J., et al. (2016). Methanotrophic production of polyhydroxybutyrate-cohydroxyvalerate with high hydroxyvalerate content. Int. J. Biol. Macromol. 87, 302-307. doi: 10.1016/j.ijbiomac.2016.02.056

Clomburg, J. M., Crumbley, A. M., and Gonzalez, R. (2017). Industrial biomanufacturing: the future of chemical production. Science 355:aag0804. doi: $10.1126 /$ science.aag0804

Conrado, R. J., and Gonzalez, R. (2014). Chemistry. envisioning the bioconversion of methane to liquid fuels. Science 343, 621-623. doi: 10.1126/science.1246929

Department of Energy (2017). Biofuels and Bioproducts from Wet and Gaseous Waste Streams: Challenges and Opportunities. Bioenergy Technologies Office. Available online at: https://www.energy.gov/sites/prod/files/2017/01/f34/ biofuels_and_bioproducts_from_wet_and_gaseous_waste_streams_full_ report_2.pdf

Eiteman, M. A., and Ramalingam, S. (2015). Microbial production of lactic acid. Biotechnol. Lett. 37:5. doi: 10.1007/s10529-015-1769-5

Flynn, J. D., Hirayama, H., Sakai, Y., Dunfield, P. F., Klotz, M. G., Knief, C., et al. (2016). Draft genome sequences of gammaproteobacterial methanotrophs isolated from marine ecosystems. Genome Announc 4:e0162915. doi: 10.1128/genomeA.01629-15

Garg, S., Clomburg, J. M., and Gonzalez, R. (2018). A modular approach for high-flux lactic acid production from methane in an industrial medium using engineered Methylomicrobium buryatense 5GB1. J. Ind. Microbiol. Biotechnol. 45, 379-391. doi: 10.1007/s10295-018-2035-3

Gilman, A., Laurens, L. M., Puri, A. W., Chu, F., Pienkos, P. T., and Lidstrom, M. E. (2015). Bioreactor performance parameters for an industrially-promising methanotroph Methylomicrobium buryatense 5GB1. Microb. Cell Fact. 14, 1-8. doi: 10.1186/s12934-015-0372-8

Hamilton, R., Kits, K. D., Ramonovskaya, V. A., Rozova, O. N., Yurimoto, H., Iguchi, H., et al. (2015). Draft genomes of gammaproteobacterial methanotrophs isolated from terrestrial ecosystems. Genome Announc. 3:e00515. doi: 10.1128/genomeA.00515-15

Hanson, R. S., and Hanson, T. E. (1996). Methanotrophic bacteria. Microbiol. Rev. $60,439-471$

Haynes, C. A., and Gonzalez, R. (2014). Rethinking biological activation of methane and conversion to liquid fuels. Nat. Chem. Biol. 10, 331-339. doi: $10.1038 /$ nchembio. 1509

Henard, C. A., Smith, H., Dowe, N., Kalyuzhnaya, M. G., Pienkos, P. T., and Guarnieri, M. T. (2016). Bioconversion of methane to lactate by an obligate methanotrophic bacterium. Sci Rep 6, 1-9. doi: 10.1038/srep21585

Henard, C. A., Smith, H. K., and Guarnieri, M. T. (2017). Phosphoketolase overexpression increases biomass and lipid yield from methane in an obligate methanotrophic biocatalyst. Metabol. Eng. 41, 152-158. doi: 10.1016/j.ymben.2017.03.007

Hosseini, S. E., and Wahid, M. A. (2014). Development of biogas combustion in combined heat and power generation. Renew. Sustain. Energy Rev. 40, 868-875. doi: 10.1016/j.rser.2014.07.204

Hwang, I. Y., Lee, S. H., Choi, Y. S., Park, S. J., Na, J. G., Chang, I. S., et al. (2014). Biocatalytic conversion of methane to methanol as a key step for development of methane-based biorefineries. J. Microbiol. Biotechnol. 24, 1597-1605. doi: 10.4014/jmb.1407.07070

Kalyuzhnaya, M. G. (2016). "Chapter 13 methane biocatalysis selecting the right microbe," in Biotechnology for Biofuel Production and Optimization, eds C. Eckert, and C. T. Trinh (Amsterdam: Elsevier), 353-383.

Kalyuzhnaya, M. G., Puri, A. W., and Lidstrom, M. E. (2015). Metabolic engineering in methanotrophic bacteria. Metabol. Eng. 29, 142-152. doi: 10.1016/j.ymben.2015.03.010
Kalyuzhnaya, M. G., Yang, S., Rozova, O. N., Smalley, N. E., Clubb, J., Lamb, A., et al. (2013). Highly efficient methane biocatalysis revealed in a methanotrophic bacterium. Nat. Commun. 4:3785. doi: 10.1038/ncomms3785

Khmelenina, V. N., Beck, D. A. C., Munk, C., Davenport, K., Daligault, H., Erkkila, T., et al. (2013). Draft genome sequence of Methylomicrobium buryatense strain 5G, a haloalkaline-tolerant methanotrophic bacterium. Genome Announc 1:13. doi: 10.1128/genomeA.00053-13

Kits, K. D., Kalyuzhnaya, M. G., Klotz, M. G., Jetten, M. S. M., Op den Camp, H. J. M., Vuilleumier, S., et al. (2013). Genome sequence of the obligate gammaproteobacterial Methanotroph methylomicrobium album strain BG8. Genome Announc. 1:e0017013. doi: 10.1128/genomeA.00170-13

la Torre, de, A., Metivier, A., Chu, F., Laurens, L. M. L., and Beck, D. A. C., Pienkos, P. T., et al. (2015). Genome-scale metabolic reconstructions and theoretical investigation of methane conversion in Methylomicrobium buryatense strain 5G(B1). Microb. Cell Fact. 14:188. doi: 10.1186/s12934-0150377-3

Myung, J., Flanagan, J. C. A., Waymouth, R. M., and Criddle, C. S. (2016). Methane or methanol-oxidation dependent synthesis of poly(3-hydroxybutyrate-co-3hydroxyvalerate) by obligate type II methanotrophs. Process Biochem. 51, 561-567. doi: 10.1016/j.procbio.2016.02.005

Narainsamy, K., Farci, S., Braun, E., Junot, C., Cassier-Chauvat, C., and Chauvat, F. (2016). Oxidative-stress detoxification and signalling in cyanobacteria: the crucial glutathione synthesis pathway supports the production of ergothioneine and ophthalmate. Mol. Microbiol. 100, 15-24. doi: 10.1111/mmi.13296

Nguyen, A. D., Hwang, I. Y., Lee, O. K., Kim, D., Kalyuzhnaya, M. G., Mariyana, R., et al. (2018). Systematic metabolic engineering of Methylomicrobium alcaliphilum $20 \mathrm{Z}$ for 2,3-butanediol production from methane. Metabol. Eng. 47, 323-333. doi: 10.1016/j.ymben.2018.04.010

Ojala, D. S., Beck, D. A. C., and Kalyuzhnaya, M. G. (2011). Genetic systems for moderately halo(alkali)philic bacteria of the genus Methylomicrobium. Meth. Enzymol. 495, 99-118. doi: 10.1016/B978-0-12-386905-0.00007-3

Pieja, A. J., Morse, M. C., and Cal, A. J. (2017). Sciencedirect methane to bioproducts: the future of the bioeconomy? Curr. Opin. Chem. Biol. 41, 123-131. doi: 10.1016/j.cbpa.2017.10.024

Puri, A. W., Owen, S., Chu, F., Chavkin, T., Beck, D. A. C., Kalyuzhnaya, M. G., et al. (2015). Genetic tools for the industrially promising methanotroph methylomicrobium buryatense. Appl. Environ. Microbiol. 81, 1775-1781. doi: 10.1128/AEM.03795-14

Soga, T., Baran, R., Suematsu, M., Ueno, Y., Ikeda, S., Sakurakawa, T., et al. (2006). Differential metabolomics reveals ophthalmic acid as an oxidative stress biomarker indicating hepatic glutathione consumption. J. Biol. Chem. 281, 16768-16776. doi: 10.1074/jbc.M601876200

Strong, P. J., Kalyuzhnaya, M., Silverman, J., and Clarke, W. P. (2016). A methanotroph-based biorefinery: potential scenarios for generating multiple products from a single fermentation. Bioresour. Technol. 215, 314-323. doi: 10.1016/j.biortech.2016.04.099

Strong, P. J., Xie, S., and Clarke, W. P. (2015). Methane as a resource: can the methanotrophs add value? Environ. Sci. Technol. 49, 4001-4018. doi: $10.1021 /$ es504242n

Whittenbury, R., Phillips, K. C., and Wilkinson, J. F. (1970). Enrichment, isolation and some properties of methane-utilizing bacteria. J. Gen. Microbiol. 61, 205-218. doi: 10.1099/00221287-61-2-205

Yan, X., Chu, F., Puri, A. W., Fu, Y., and Lidstrom, M. E. (2016). Electroporationbased genetic manipulation in type I methanotrophs. Appl. Environ. Microbiol. 82, 2062-2069. doi: 10.1128/AEM.03724-15

Conflict of Interest Statement: The authors declare that the research was conducted in the absence of any commercial or financial relationships that could be construed as a potential conflict of interest.

Copyright (c) 2018 Henard, Franklin, Youhenna, But, Alexander, Kalyuzhnaya and Guarnieri. This is an open-access article distributed under the terms of the Creative Commons Attribution License (CC BY). The use, distribution or reproduction in other forums is permitted, provided the original author(s) and the copyright owner(s) are credited and that the original publication in this journal is cited, in accordance with accepted academic practice. No use, distribution or reproduction is permitted which does not comply with these terms. 